Revista Monografias Ambientais - REMOA v. 15, n.1, jan-abr. 2016, p.337-346

Revista do Centro de Ciências Naturais e Exatas - UFSM, Santa Maria

\title{
AVALIAÇÃO DO PROCESSO DE SENSIBILIZAÇÃO DOS ALUNOS DO CAP-UERJ SOBRE A ÁGUA E O SISTEMA DE CAPTAÇÃO E ARMAZENAMENTO DE ÁGUAS PLUVIAIS
}

\author{
Evaluation of the Process of Students Awareness on Rain Water Harvesting and Storage \\ Suéllen da Silva Pereira ${ }^{1}$, Alfredo Akira Ohnuma Júnior ${ }^{2}$, \\ Luciene Pimentel da Silva ${ }^{2}$ \\ ${ }^{1}$ Universidade do Estado do Rio de Janeiro - UERJ, Rio de Janeiro, Brasil \\ 2 PEAMB, UERJ, Rio de Janeiro, Brasil
}

\begin{abstract}
Resumo
O tema água é muito recorrente nos dias atuais diante da crise hídrica em diversos municípios brasileiros. Portanto, é necessário buscar alternativas para mudanças nas práticas de utilização deste recurso, bem como criar mecanismos estruturantes ou não -estruturantes que possam contribuir na gestão dos usos múltiplos da água. Este trabalho tem como objetivo avaliar o processo de sensibilização dos alunos do Instituto de Aplicação Fernando Rodrigues da Silveira da Universidade do Estado do Rio de Janeiro (CAp-UERJ), os métodos de avaliação da pesquisa integraram aplicação de questionários aos alunos do $2^{\circ}$ e $5^{\circ}$ de escolaridade dos Anos Iniciais do Ensino Fundamental, a partir da conscientização realizada com a contribuição do sistema de captação de águas pluviais instalado no espaço escolar, proporcionando ferramentas práticas de aprendizagem. Os resultados indicaram que $66 \%$ dos alunos apresentaram algum domínio do tema, além de demonstrarem argumentos que buscam a racionalização no uso da água.
\end{abstract}

Palavras-chave: Educação Ambiental, Percepção dos alunos, Uso racional da água, Águas Pluviais.

Abstract

Water is a very recurrent thematic, especially during the water crisis that a number of Municipalities in Brazil have been facing recently. Therefore, it is necessary to seek alternatives for changes in practices of water use as well as to create structural and non-structural measures to support the management of multiple uses of water. The main objective of this research was to evaluate at Instituto de Aplicação Fernando Rodrigues da Silveira da Universidade do Estado do Rio de Janeiro (CAp-UERJ) the level of students' perception and their sensibility about the uses of water and its rational application. The methodology involved a survey among students of the $2^{\text {nd }}$ and $3^{\text {rd }}$ years of primary school, using a rainfall harvesting system built in the School, as socio environmental motivator, providing a practical learning tool. Results indicated that $66 \%$ of total students demonstrated to know about this thematic and showed evidences of previous knowledge about rational use of water.

Keywords: Environmental education, Students perception, Rational use of water, Rainwater 


\section{Introdução}

A carência de políticas públicas para promoção do uso racional da água, como também na gestão sustentável dos recursos hídricos, contribuiu para os problemas de insuficiência dos sistemas de abastecimento de água em vários municípios durante a chamada crise hídrica. Além desses fatores, o uso inadequado da água traz preocupações, uma vez que tendem a acentuar a sua indisponibilidade.

É comum presenciar o desperdício, tanto no ambiente domiciliar quanto em instituições públicas, inclusive aquelas que recentemente têm se dedicado à promoção de valores voltados à sustentabilidade ambiental, como é o caso da escola (ALMEIDA, 2010).

Monzani (2009) realizou um estudo no Colégio Agrícola Senador Carlos Gomes de Oliveira, nos quais questionários foram aplicados aos alunos do colégio para quantificar o consumo de água. Os alunos demonstraram ter consciência sobre seus desperdícios quando $80 \%$ afirmaram que o maior desperdício ocorre devido aos seus próprios descuidos. No mesmo estudo, Monzani obsevou que 38\% de redução do consumo podem ser alcançados nas mudanças de hábitos escolares.

Fazola (2011) defende em seu mapeamento de consumo realizado em cada ambiente das escolas que o aparelho sanitário e, principalmente, os banheiros são os responsáveis pelas maiores parcelas de consumo de água na escola e que não estão somente relacionados aos descuidos dos alunos.

O consumo de água varia de uma unidade para outra unidade escolar, sobretudo em função das categorias de ensino. Santos (2007) apresenta em uma escola na comunidade rural que o desperdício de água é algo observado pelos alunos do $6^{\circ}$ ano do Ensino Fundamental.

Os sistemas de captação, armazenamento e aproveitamento de água pluvial, quando instalados em ambientes escolares, podem contribuir no processo de sensibilização dos alunos, uma vez que novas abordagens de ensino, quando vivenciadas na prática, podem ser utilizadas enriquecendo o processo de aprendizagem.

Além disso, o sistema de captação de água pluvial e o seu aproveitamento é uma alternativa técnica da engenharia e que também é considerado vantajoso na diminuição do consumo de água potável (PEIXE, 2012).

Diante desta abordagem, foi instalado no Instituto de Aplicação Fernando Rodrigues da Silveira da Universidade do Estado do Rio de Janeiro (CAp-UERJ) um sistema de captação de águas pluviais, no intuito de desenvolver soluções em edificações no meio urbano na utilização da água em um ambiente escolar.

Como forma de envolver a comunidade escolar, a Educação Ambiental tem sido aplicada como instrumento que contribui no processo de transformação da percepção dos alunos, proporcionando também mudanças nas práticas relacionadas ao meio ambiente. Segundo Ab 'Saber (1991), a Educação Ambiental deve fornecer subsídios para a sociedade ampliar as discussões e ações concretas em relação às questões ambientais, no contexto da educação básica, promovendo a reprodução e a transformação de um pensamento em prática.

Contudo, a Educação Ambiental quando desenvolvida no âmbito do uso da água e do consumo consciente tem importância à população escolar e infantil, que demonstra grande facilidade de assimilação de conceitos de conservação e um poder de projeção do tema no ambiente familiar, de modo que se tornem processos perenes ao projeto. (ALVES, 1999).

Castro, Silva e Silva (2009) afirmam a percepção ambiental como a forma pela qual os seres humanos ficam a par dos objetos e transformações que se manifestam ao seu entorno, buscando compreender a relação entre o homem e meio ambiente.

Ao promover esta iniciativa, é importante definir quais as ferramentas serão adotadas no âmbito da Educação Ambiental, no presente artigo foi delineada a percepção ambiental dos alunos de diversas formas, sendo apresentados os resultados alcançados a partir de análise quali-quantitativa dos questionários aplicados. Neste intuito, o presente artigo tem como objetivo avaliar o processo de 
sensibilização do uso da água pelos alunos do CAp-UERJ de acordo com os resultados alcançados no questionário.

\section{Metodologia}

\section{1 Área de Estudo e o Sistema de Águas Pluviais}

A presente pesquisa teve como área de estudo a cobertura da quadra poliesportiva do CApUERJ, localizado no município do Rio de Janeiro, no bairro de Rio Comprido (Figura 1).

O CAp-UERJ compreende atividades do Projeto HIDROCIDADES, que compõe a Rede de Pesquisa de Manejo de Águas Pluviais em Meio Urbano (MAPLU2/FINEP, 2011), cujo objetivo geral consiste em desenvolver soluções urbanísticas para o manejo adequado das águas pluviais, assim como desenvolver ações que contribuam para o aumento da conscientização dos problemas associados ao abastecimento de água. O sistema de captação de águas pluviais foi instalado em março de 2013 e utiliza como área de captação de $80 \mathrm{~m}^{2}$ de parte da cobertura da quadra poliesportiva, com volume de armazenamento principal de 2460 litros.

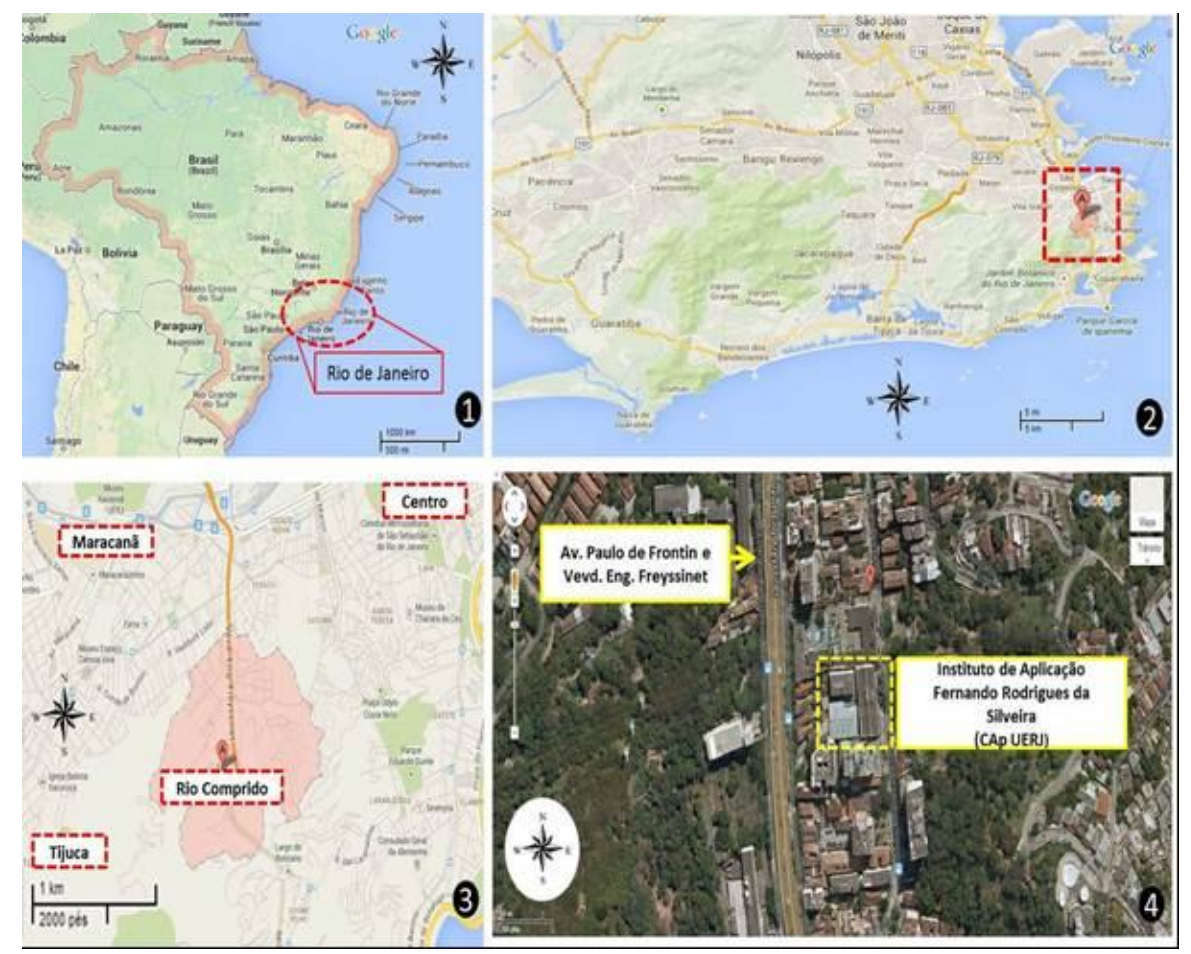

Figura 1: Localização de área do CAp-UERJ, Bairro Rio Comprido, Rio de Janeiro

\subsection{Definição dos Alunos Envolvidos}

Antes de iniciar o projeto de pesquisa na instituição de ensino, foram realizadas reuniões com os professores e coordenadores do CAp-UERJ para avaliar a seleção de grupos participantes de modo compatível com as disciplinas e a ementa de curso. Na reunião foram utilizadas perguntas norteadoras que abrangeram os seguintes enfoques: i) quais anos potenciais para aplicação dos questionários; ii) qual metodologia utilizar; iii) qual conteúdo abordado pelos professores sobre a água, consumo e o sistema de captação das águas pluviais.

Após a realização de entrevistas e reuniões com os professores, foi definida com base no plano de curso do CAp-UERJ os alunos do $2^{\circ}$ e do $5^{\circ}$ dos Anos Iniciais. Além disso, não foram utilizadas outras turmas, pois o intuito foi conhecer também a percepção de um grupo que saiu recentemente da alfabetização e de outro grupo que deixará os anos iniciais para continuar os seus estudos no Ensino 
Fundamental II.

\subsection{Desenvolvimento das Atividades}

A metodologia atendeu o fluxograma de atividades da Figura 2. A primeira etapa foi à elaboração de perguntas do questionário realizadas em consulta aos especialistas da área de Recursos Hídricos e professores dos alunos dos Anos Iniciais do CAp-UERJ. Em seguida, foi realizada a validação do instrumento de acordo com a metodologia de Delphi, na qual o questionário elaborado é apresentado a um grupo de alunos não envolvidos no processo (WRIGHT \& GIOVINAZZO, 2000). Segundo Silva (2009), a validação do instrumento nessa pesquisa, o questionário, serve para evitar que uma mesma opção possa gerar diferentes significados ou análises. A validação é útil para que a linguagem utilizada no questionário fique mais próxima da linguagem dos alunos.

Adiante, foi aplicado o questionário cujo objetivo foi conhecer a percepção dos alunos sobre os diferentes usos da água para consumo humano e também se possuíam conhecimento da operação de um determinado sistema de captação e armazenamento de águas pluviais.

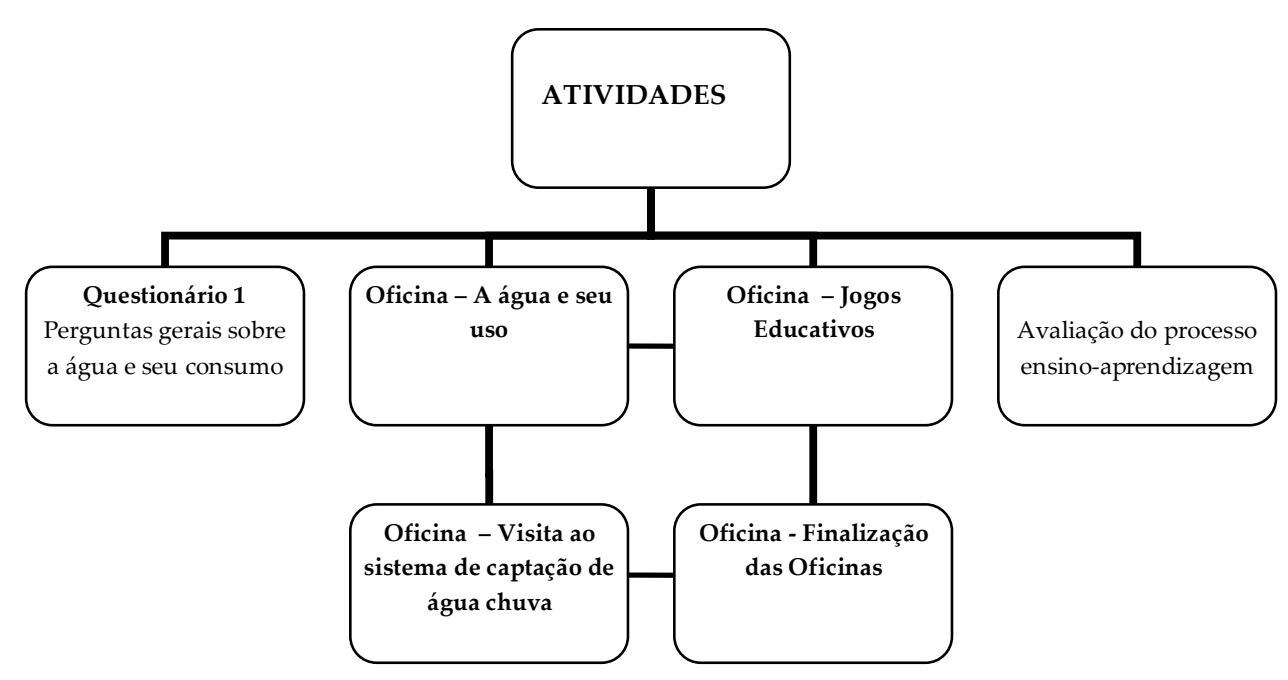

Figura 2 - Fluxograma de Atividades Realizadas com os Alunos do $2^{\circ}$ e $5^{\circ}$ dos Anos Iniciais.

Na sequência, os alunos participaram de quatro oficinas de sensibilização e conscientização planejadas e estruturadas de acordo com a faixa etária, de modo a fomentar a interação no processo de ensino aprendizagem.

Os resultados alcançados neste processo de avaliação foram obtidos a partir do cálculo de um Ranking Médio (RM) adotado para analisar quantitativamente as respostas.

\subsection{Avaliação dos Questionários - Ranking Médio}

No estudo de análise quantitativa para avaliação da percepção, os resultados foram consolidados a partir das respostas obtidas com o questionário, sendo utilizada a escala tipo Likert, adaptada

A escala Likert é utilizada em pesquisas empíricas, em especial quantitativas organizacionais, sendo a definição da escala de medida apropriada para a coleta de informações (ALEXANDRE et al. 2003). Em geral, são utilizadas na escala Likert quatro ou cinco categorias ordinais, como exemplo, 0 muito baixo, 1- baixo, 2- médio, 3- alto e 4 muito alto, as respostas para cada item variam segundo grau de intensidade.

No presente artigo, a escala Likert foi adaptada, ou seja, o grau de intensidade das respostas dos 
questionários foi substituída por valores entre 0 e 4 de acordo com o grau de acerto e de dificuldade das respostas concedidas ao questionário. Portanto, os valores 4,3 e 2 foram adotados para respostas certas de acordo com o grau de dificuldade DIFÍCIL, MÉDIO e FÁCIL, respectivamente. O valor 1 foi adotado para as respostas erradas e o valor 0 seria considerado "indiferente" ou "sem opinião", sendo o "ponto neutro", equivalente aos casos em que os respondentes deixaram em branco (Tabela 1).

Tabela 1-Respostas do Questionário

\begin{tabular}{lcccc}
\hline \multirow{2}{*}{ PONTUAÇÃO } & \multicolumn{4}{c}{ QUESTIONÁRIOS/PERGUNTAS } \\
\cline { 2 - 5 } & Resposta Certa & Resposta Errada & $\begin{array}{c}\text { Resposta } \\
\text { Branco }\end{array}$ & em \\
\hline Pergunta Nível Difícil & 4 & 1 & 0 \\
\hline Pergunta Nível Médio & 3 & 1 & 0 \\
\hline Pergunta Nível Fácil & 2 & 1 & 0 \\
\hline
\end{tabular}

A partir da ponderação das respostas do questionário, foi possível pontuar o número de respostas certas e erradas de cada aluno.

É importante destacar que, a mensuração da pergunta avaliada em difícil, médio ou fácil foi desenvolvida a partir de instrumentos qualitativos com os professores e alunos, como entrevistas e a observação participante. Este último tem como objetivo, observar o grupo de alunos e conhecer as suas atitudes e perspectivas em sala de aula, considerando as especificidades de cada grupo.

\section{Resultados e Discussões}

Os resultados apresentados referem-se às análises quantitativas do questionário aplicado com os alunos que participaram de todo o processo de sensibilização. Responderam ao questionário 101 alunos no total (Tabela 1).

Tabela 1 - Número de alunos que responderam aos questionários

\begin{tabular}{c|c}
\hline Série & Questionário 1 \\
\hline $2^{\circ}$ Ano Inicial & 55 alunos \\
\hline $5^{\circ}$ Ano Inicial & 46 alunos \\
\hline Total & 101 alunos \\
\hline
\end{tabular}

O questionário 1 foi elaborado com 13 perguntas de múltipla escolha estruturadas em três grandes blocos:

- Pergunta 1 a 3 referentes ao conhecimento geral sobre a água;

- Pergunta 4 a 8 referentes à água pluvial;

- Pergunta 9 a 13 abordam o sistema de captação de águas pluviais e consumo;

As perguntas realizadas no questionário são apresentadas na Tabela 2 de acordo com o seu nível de dificuldade, respeitando a ordem em que foram apresentadas para os alunos. 
Tabela 2 - Perguntas elaboradas para Questionário 1

\begin{tabular}{|c|c|c|}
\hline Nível da Pergunta: Fácil & Nível da Pergunta: Médio & Nível da Pergunta: Difícil \\
\hline $\begin{array}{l}\text { 1)A água é um recurso que } \\
\text { pode acabar? }\end{array}$ & $\begin{array}{l}\text { 3) Onde você acha que o } \\
\text { CAp- UERJ utiliza mais a } \\
\text { água? }\end{array}$ & $\begin{array}{l}\text { 10) O que é um sistema de } \\
\text { captação de água da chuva? }\end{array}$ \\
\hline $\begin{array}{l}\text { 2)Se você respondeu SIM à } \\
\text { pergunta de } n^{\circ} 1 \text {, assinale } \\
\text { como a água pode acabar }\end{array}$ & $\begin{array}{l}\text { 5) Qual é a principal } \\
\text { importância da água da } \\
\text { chuva? Marque somente uma } \\
\text { opção. }\end{array}$ & $\begin{array}{l}\text { 11) Há lugares que recolhem } \\
\text { a água da chuva. Isso se } \\
\text { chama captação de água da } \\
\text { chuva. A captação e } \\
\text { aproveitamento de água de } \\
\text { chuva podem ser realizados } \\
\text { por qualquer pessoa e em } \\
\text { qualquer lugar? }\end{array}$ \\
\hline $\begin{array}{l}\text { 4)A água da chuva é } \\
\text { importante? }\end{array}$ & $\begin{array}{l}\text { 6)Você acha que a água da } \\
\text { chuva pode ser utilizada? }\end{array}$ & $\begin{array}{l}\text { 12)Quantos litros de água no } \\
\text { total, você consome por dia? }\end{array}$ \\
\hline $\begin{array}{l}\text { 7)Se você respondeu SIM à } \\
\text { pergunta de } n^{\circ} 6 \text {, assinale } \\
\text { como a água da chuva pode } \\
\text { ser utilizada. Marque } \\
\text { somente uma opção }\end{array}$ & $\begin{array}{l}\text { 8)Precisamos fazer algum } \\
\text { tratamento na água da chuva } \\
\text { antes de utilizar? }\end{array}$ & $\begin{array}{l}\text { 13) Quantos litros de água } \\
\text { você acha que consome em } \\
\text { uma descarga sanitária? }\end{array}$ \\
\hline - & $\begin{array}{l}\text { 9)O que é consumir água de } \\
\text { maneira consciente? }\end{array}$ & - \\
\hline
\end{tabular}

Das perguntas elaboradas no questionário, quatro foram consideradas difíceis (Figura 3), cinco médias (Figura 4) e quatro fáceis (Figura 5). A partir das respostas, foi realizada uma média do número de alunos que responderam corretamente às questões pelo seu nível de dificuldade.

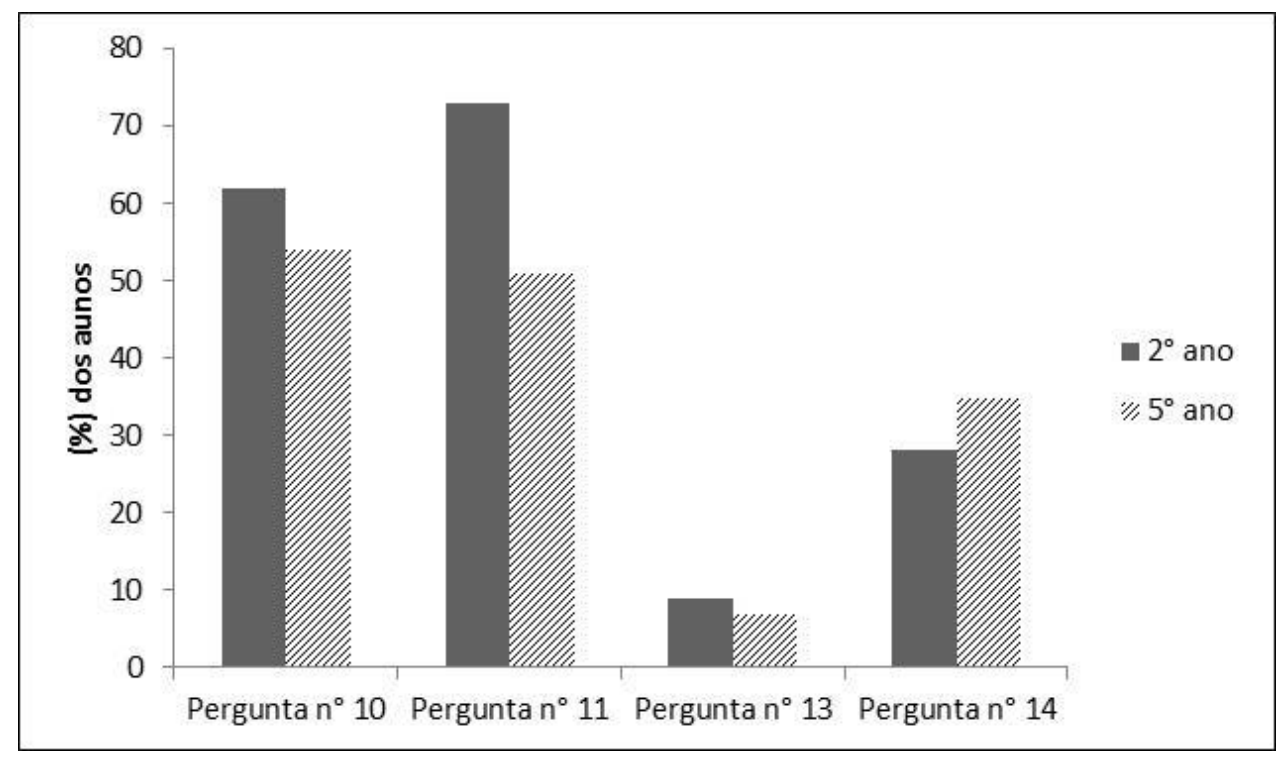

Figura 3 - Porcentagem dos Alunos que Responderam Corretamente as Perguntas Consideradas Difíceis.

De acordo com a Figura 3, observa-se que a grande maioria dos alunos respondeu corretamente as perguntas de $n^{\circ} 10$ e $n^{\circ} 11$ que se referem ao sistema de captação de água pluvial. As perguntas de $n^{\circ}$ 
12 e $\mathrm{n}^{\circ} 13$ que aborda sobre consumo gerou certa dificuldade, uma vez que o número de alunos que acertou é menor que 30\%. É importante destacar o nível de dificuldade em quantificar o consumo diário de água armazenada em um reservatório ou utilizada para consumo humano tanto para um adulto como para criança. Portanto, era esperado um menor número de acerto nessas questões.

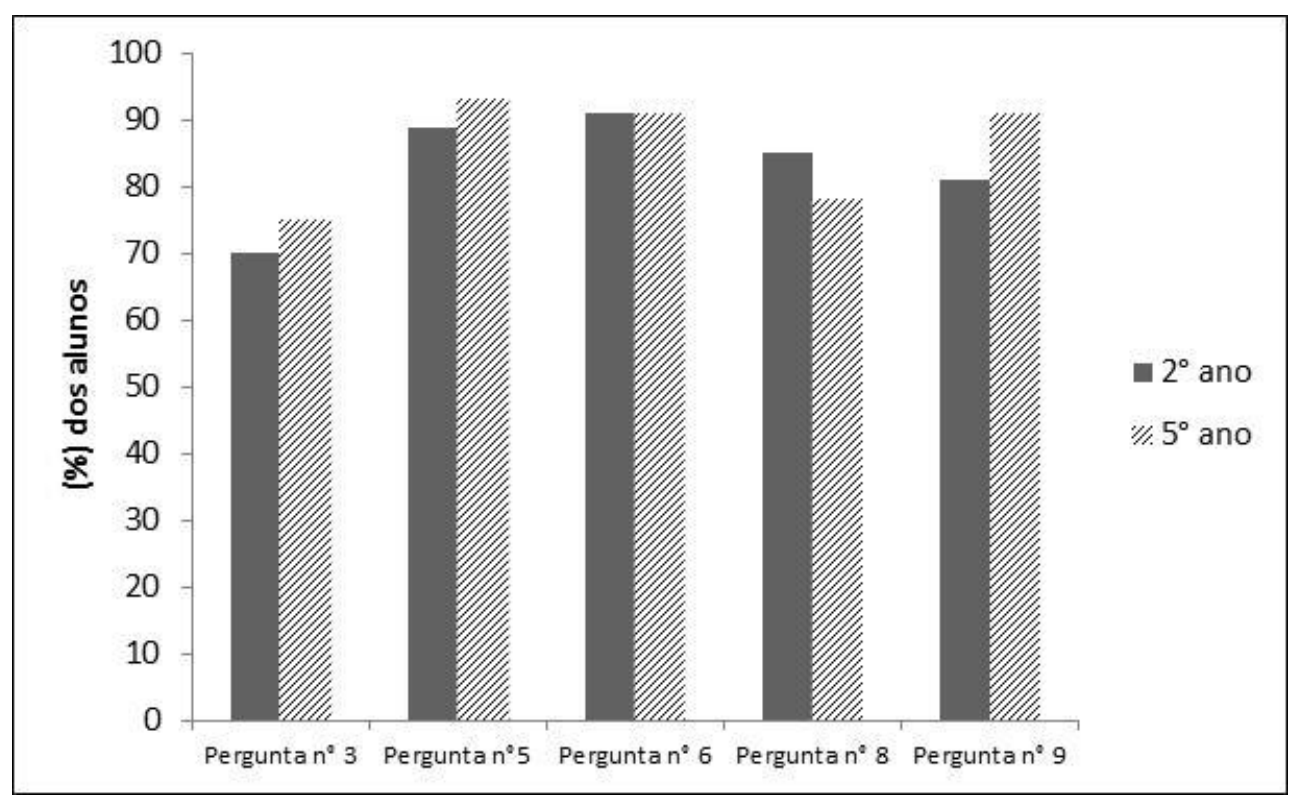

Figura 4 - Porcentagem dos Alunos que Responderam Corretamente as Perguntas Consideradas com Grau de Dificuldade Médio.

Diferentemente da Figura 3, grande parte dos alunos (acima de 70\%) respondeu corretamente aos questionamentos apresentados. Não houve certo grau de dificuldade como ocorreu com as perguntas de número 13 e 14 (apresentadas anteriormente). Apenas a pergunta de número 3 que gerou uma proporção menor de acertos, isto pode ter ocorrido devido à falta de informações disponíveis para que os alunos soubessem o principal consumo de água no CAp-UERJ.

Enquanto as perguntas consideradas fáceis (Figura 5), a número 2 apresentou certa ambiguidade e inúmeros alunos marcaram a opção incorreta, o mesmo ocorreu com a pergunta de número 7 que era apenas para assinalar uma opção e diversos alunos marcaram mais de uma. 


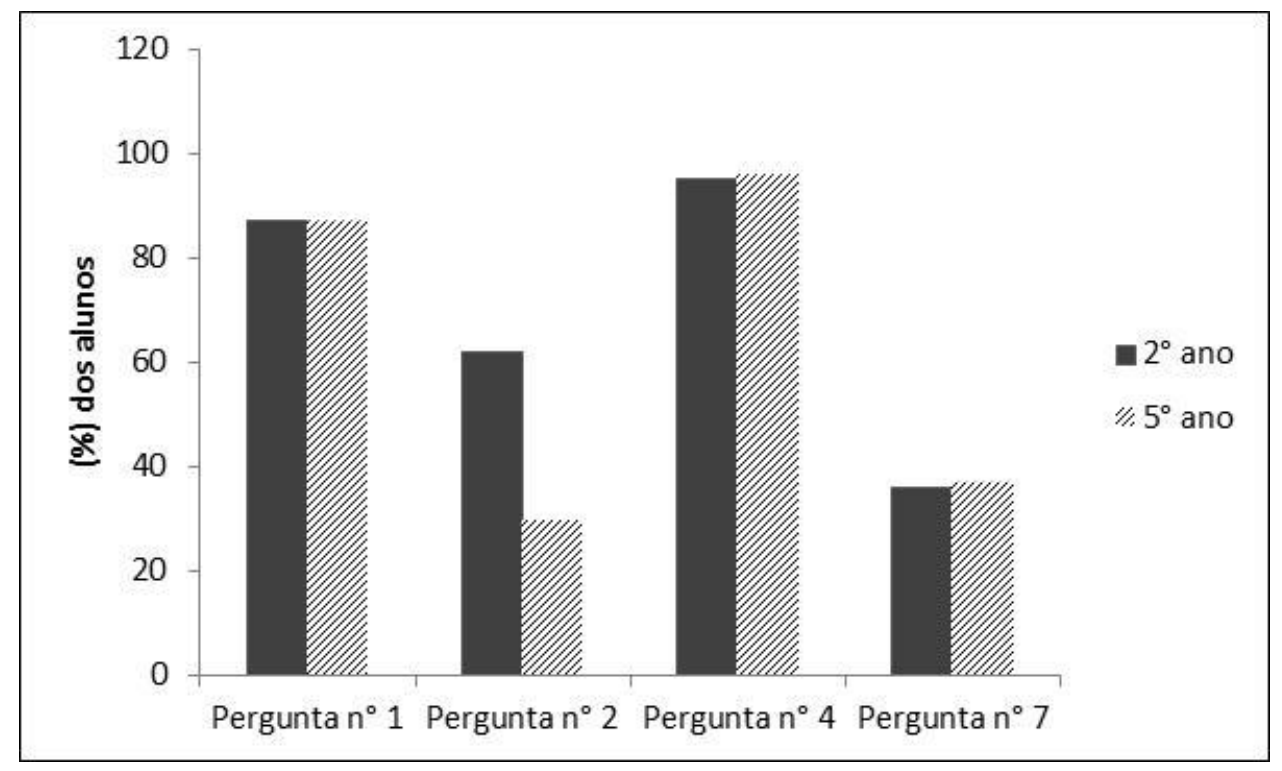

Figura 5 - Porcentagem dos Alunos que Responderam Corretamente as Perguntas Consideradas com Grau de Dificuldade Fácil.

A partir dos resultados apresentados, foi possível constatar por uma média calculada entre o número de alunos e o número de pontos realizados nos questionários que, $66 \%$ dos alunos marcaram as respostas corretas. Portanto, antes de iniciar o processo de sensibilização, grande parte dos alunos apresentava conhecimento do tema abordado e no decorrer das atividades demonstrou preocupação com o conteúdo que estava sendo evidenciado.

Em uma pesquisa similar realizada na escola localizada no município de Nossa Senhora da Glória, em Sergipe, os resultados apresentaram que apesar dos alunos possuírem conhecimento sobre a escassez da água, suas práticas demonstraram que não existia conscientização na forma de consumo da água, uma vez que $80 \%$ dos entrevistados afirmaram que se ensaboava com o chuveiro ligado (SOUZA, 2010).

Contudo, quando questionados sobre o fato de conhecerem algum projeto de intervenção no desperdício da água grande parte dos alunos (73\%) não possuía conhecimento.

É evidenciado que, os alunos de certa maneira, compreendem que suas ações podem influenciar no consumo e desperdício de água. Entretanto, não são todas as escolas que desenvolvem iniciativas que diversifiquem o processo educativo no âmbito socioambiental. Segundo Almeida (2009), faz-se necessário o emprego de uma metodologia na Educação Ambiental capaz de promover nas escolas um conhecimento integral das questões socioambientais e do uso consciente da água.

Portanto, trabalhar com a disseminação de uma cultura de conservação da água a partir do seu uso racional alcança alto nível de importância. As iniciativas educacionais para o consumo sustentável, racional e consciente podem ser realizadas no âmbito dos currículos do Ensino Fundamental e Médio. A conscientização do uso racional da água é uma necessidade atual já que medidas educativas que alterem hábitos podem ser fatores efetivos na redução de tarifação de água, além de minimizar os gastos excessivos com este recurso natural (ALMEIDA, 2009).

\section{Conclusões}

Ao avaliar o processo e os resultados obtidos com a aplicação do questionário, foi observado que os alunos do CAp-UERJ possuem grande interesse e conhecimento pelo tema. Os professores e 
coordenadores buscam a partir da proposta pedagógica do Instituto, refletida nos planos de cursos, desenvolver junto com os alunos outras experiências e meios de aprendizagem. O desenvolvimento de projetos cuja vivência do aluno seja levada em consideração no processo de ensino-aprendizagem, de forma participativa reflete nos resultados do questionário, por meio do qual foram avaliados como positivos, tendo em vista que $66 \%$ dos alunos responderam corretamente aos questionamentos apresentados. E, ainda, participaram efetivamente de todo o processo de sensibilização em que foram envolvidos, demonstrando preocupação, entendimento e ainda mudanças nas práticas de utilização da água.

Estes resultados corroboram para que possíveis iniciativas sejam desenvolvidas em espaços escolares de forma a promover mudanças de práticas dos alunos, funcionários e professores. Recomendam-se como trabalhos futuros, novas perspectivas de pesquisa entre outros grupos de alunos e funcionários ampliando os instrumentos metodológicos para consumo de água e conhecimento da percepção ambiental.

Além disso, com o equipamento instalado no CAp-UERJ será possível verificar, se houve uma diminuição no consumo de água, após a utilização do equipamento.

Para que seja realizada a etapa sucessiva a pesquisa iniciada no CAp-UERJ, é imprescindível a continuidade do apoio e o incentivo da direção da escola. Isso torna o projeto mais consolidado, uma vez que o grau de envolvimento dos estudantes no projeto pode ser refletido pela motivação dos professores e funcionários.

\section{Referências}

AB'SABER, A. Nacib. (Re) conceituando educação ambiental. Rio de Janeiro: MASTMuseu de Astronomia e Ciências Afins, 1991. 1p

ALEXANDRE, C.W.J; Andrade F.D.; Vasconcelos P.A.; Araujo S.M.A.; Batista J.M. Análise do Número de Categorias da Escala de Likert Aplicada à Gestão pela Qualidade Total através da Teoria da Resposta ao Item. In: XXIII Encontro Nacional de Engenharia de Produção - Ouro Preto, MG. 2003

ALMEIDA, M.A.S. Disseminação da Cultura da Avaliação de Conformidade no Ensino da Rede Federal e Educação Profissional, Ciência e Tecnológica. Inmetro 2009.

ALMEIDA, K. D.S., Simão, M.O.A.R. (2010). A Percepção de Alunos do Ensino Médio sobre o Desperdício de Água no Ambiente Escolar: Estudo de Caso em Duas Escolas Públicas em Manaus.

ALVES, W. C. Programa de economia de água de Santo André: desenvolvimento de metodologias, planejamentos e procedimentos operacionais visando o combate às perdas de água em setor piloto de sistema público de distribuição. In: CONGRESSO BRASILEIRO DE ENGENHARIA SANITÁRIA E AMBIENTAL, 20 1999, Rio de Janeiro. Associação Brasileira de Engenharia Ambiental, 1999.

CASTRO, F.D.; SILVA, V. P.; SILVA, A. B. Percepção ambiental de donas de casa de Guaramaré/RN quanto a produção de petróleo e qualidade de vida. In: IV Congresso de Pesquisa e Inovação da Rede Norte e Nordeste da Educação Tecnológica. Belém, 2009. Disponível em: <http://www.ufrgs.br/seerbio/ojs/index.php/rbb/article/view/1178>. Acesso em: 9 jul. 2012.

FAZOLA, G. B., GHISI. Potencial de Economia de Água em duas Escolas em Florianópolis em Santa Catarina. Ambiente Construído. Porto Alegre V. 11 n. 4 p. 65-78. Associação Nacional de Tecnologia do Ambiente Construído. 2011. 
MONZANI, R.M.; LONGHI, C.; SILVA, S. A.; CAMPOS, J.F.S. Consumo de Água Pela Comunidade Escolar Do Colégio Agrícola Senador Carlos Gomes De Oliveira, Conscientização Do Uso E Formas De Tratamento. In: III Mostra Nacional de Iniciação Científica e Tecnológica Interdisciplinar, 2009, Camboriú. Anais da III Mostra Nacional de Iniciação Científica e Tecnológica Interdisciplinar, 2009. v. 1.p. 1-100.

PEIXE, C.R.S. 2012. Águas Pluviais para Usos Não Potáveis em Escolas Municipais: Estudo de Caso na Região da Baixada de Jacarepaguá - RJ. Tese de Dissertação. Universidade do Estado do Rio de Janeiro. Centro de Tecnologia e Ciências - Faculdade de Engenharia.

SANTOS, E. de O. C., SANTOS, D. N. dos, BRITO, L. T. de L.; SILVA, A. de S. , 2007 Experiência Brasileira sobre Captação, Armazenamento, Gestão e Qualidade da Água de Chuva para Consumo Humano em Comunidades Rurais do Haiti. In: Simpósio Brasileiro de Captação e Manejo de Água de Chuva. 6. 2007. Belo Horizonte- MG. Anais... Petrolina - PE: ABCMAC.

SILVA, Construção e Validação de um questionário de Atitudes frente às relações- Encontro Nacional de Pesquisa em Educação em Ciências VII Enpec. Florianópolis 11p. 2009.

SOUZA, A.A.C.; GOMES,L.J.Percepção e Desperdício da Água Pelos Estudantes de Uma Escola Urbana no Município de Nossa Senhora da Glória/SE. In: III Encontro de Recursos Hídricos em Sergipe. Sergipe 2010.

WRIGHT, J.T.C. \& GIOVINAZZO,R.A. 2000. Delphi - Uma ferramenta de apoio ao planejamento Prospectivo. Caderno de Pesquisas em Administração. São Paulo. V. 01, no 12, 2oㅡ trim. 